\title{
Tobacco and Alcohol Use and Clinical Staging of Head and Neck Tumors
}

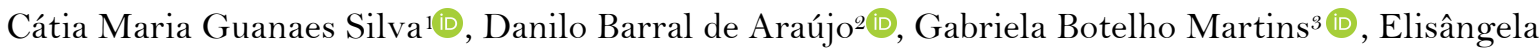 \\ de Jesus Campos² ${ }^{\mathbb{D}}$, Roberto Paulo Correia de Araújo ${ }^{4}$ (D)
}

\begin{abstract}
${ }^{1}$ Department of Propaedeutics and Integrated Clinic, Faculty of Dentistry, Federal University of Bahia, Salvador, BA, Brazil.

${ }^{2}$ Department of Biochemistry and Biophysics, Institute of Health Sciences, Federal University of Bahia, Salvador, BA, Brazil.

${ }^{3}$ Department of Physiotherapy, Institute of Health Sciences, Federal University of Bahia, Salvador, BA, Brazil.

${ }^{4}$ Graduate Program in Interactive Processes of Organs and Systems, Institute of Health Sciences, Federal University of Bahia, Salvador, BA, Brazil.
\end{abstract}

Author to whom correspondence should be addressed: Prof. Dr. Roberto Paulo Correia de Araújo, Instituto de Ciências da Saúde, Programa de Pós Graduação em Processos Interativos dos Órgãos e Sistemas, Av. Reitor Miguel Calmon, s/n, sala 410, Vale do Canela, Salvador, BA, Brazil.40.160-100. Phone: +55 7132838191. E-mail: rpcaraujo@hotmail.com.

Academic Editors: Alessandro Leite Cavalcanti and Wilton Wilney Nascimento Padilha

Received: 27 December 2019 / Accepted: 19 May 2020 / Published: 01 June 2020

How to cite this article: Silva CMG, Araújo DB, Martins GB, Campos EJ, Araújo RPC. Tobacco and alcohol use and clinical staging of head and neck tumors. Pesqui Bras Odontopediatria Clín Integr. 2020; $20: e 5638$. https://doi.org/10.1590/pboci.2020.096

\begin{abstract}
Objective: To determine the relationship between tobacco and alcohol consumption and staging of head and neck cancer in patients treated at a referral hospital for cancer treatment. Material and Methods: This is a cross-sectional study based on medical records of patients with head and neck cancer treated between 2008 and 2015. The following variables were considered: gender, age, marital status, educational level, place of residence, profession, affected site, clinical staging of neoplasms, histopathological diagnosis, tobacco and alcohol consumption. Results: Of the 154 medical records analyzed, there was a predominance of male patients $(72.7 \%)$, single $(50 \%)$, with low education $(88.1 \%)$, rural workers $(38.3 \%)$, residents in the state countryside $(70.2 \%)$ and aged $20-94$ years. T3 and T4 size tumors prevailed. A significant correlation was found between alcohol use and tumor size $(\mathrm{p}=0.03)$ and presence of nodules $(\mathrm{p}<0.001)$, as well as between alcohol use and smoking with tumor size $(\mathrm{p}=0.04)$ and presence of nodules $(\mathrm{p}=0.019)$. No correlations were observed between tobacco use and injury staging. Conclusion: There was strong significance between tumor size and presence of nodules, both with the use of alcohol alone and with tobacco, thus suggesting the existence of important carcinogenic action of this substance.
\end{abstract}

Keywords: Head and Neck Neoplasms; Mouth Neoplasms; Salivary Gland Neoplasms. 


\section{Introduction}

Head and neck cancer (HNC) is a complex malignant neoplasm that involves vital anatomical structures, which makes its treatment difficult [1]. The National Cancer Institute's estimates for the 20182019 biennium stipulate that, for Brazil, 11,200 new cases of oral cavity cancer among men and 3,500 among women will appear each year, while for laryngeal cancer, estimates are 6,390 new cases among men and 1,280 among women each year [2].

Despite the fact that the survival pattern for individuals with oral cancer is $50 \%$, very little has been done in an attempt to correlate the influence of risk factors on the appearance of potentially malignant lesions and oral cancer [3].

Alcohol and tobacco are recognized worldwide as the most important risk factors for the development of squamous cell carcinoma of the oral cavity and pharynx and have a synergistic effect [2,4]. The interaction patterns between tobacco and alcohol have been variable, being represented by multiplicative or additive effects between both, with a multiplicative effect of risk in their association. Analyses have suggested that, in general, "heavy" smokers are also "heavy" drinkers, and sometimes the assessments of the effects of these habits alone are inconsistent [5].

Different types and uses of tobacco and alcohol can characterize incidence and mortality from oral cancer in different regions of Brazil [6,7]. Other parameters such as age, sex, educational level, occupation and socioeconomic status also influence the development of these injuries [3].

Despite diagnostic advances in recent decades, around $55 \%$ of patients are still diagnosed with advanced stages in Europe [1]. In Brazil, studies confirm the late diagnosis, characterizing a population of difficult treatment and disease control [8-10].

The frequent occurrence and high lethality of HNC in Brazil give great importance to the problem that is considered a relevant public health problem. Special attention should be given to monitoring, characterizing populations at risk and optimizing the definition of public health policies aimed at prevention, protection and assistance to patients $[11,12]$.

The aim of this study was to determine the relationship between tobacco and alcohol consumption and the staging of $\mathrm{HNC}$ in patients treated at a referral hospital for cancer treatment in the city of Salvador, Brazil, between years 2008 and 2015.

\section{Material and Methods}

Study Design

This is a retrospective descriptive-analytical study involving confirmed cases of head and neck cancer based on the medical records of patients treated at the "Aristides Maltez” Hospital (HAM), Salvador, Bahia, Brazil.

\section{Population and Sample}

Sample selection was carried out based on an official list of medical records of all patients enrolled / treated at the Head and Neck Service of the Hospital between January 2008 and December 2015. For this purpose, 722 medical records were randomly selected, which composed the convenience sample used in this research.

Individuals with a confirmed diagnosis of oral and oropharyngeal cancer regularly enrolled and treated at HAM in the study period were included in the present study. Exclusion criteria covered patients 
diagnosed with other cancer subtypes, even in head and neck, including thyroid and skin, as well as those who, after initial consultation, discontinued treatment. Additionally, medical records with incomplete data related to the disease were also excluded. Therefore, 154 medical records were included in the present study.

\section{Data Collection}

Data were collected by a trained researcher. Information about sex, age, marital status, educational level, place of residence, profession, affected site, clinical staging of neoplasms, histopathological diagnosis, tobacco and alcohol consumption and oral hygiene level were collected and recorded in a specific form.

\section{Data Analysis}

Data were organized and tabulated using Excell software (Microsoft ${ }^{\circledR}$ Office 2007), being presented through descriptive statistics (absolute and percentage distribution). Pearson's Chi-square test was used for categorical variables and Likelihood Ratio Chi-Square to investigate possible associations among variables belonging to the TNM classification and risk factors related to alcohol and tobacco consumption. The software used was Epi Info - version 6.04, with significance level was set at 5\%.

Ethical aspects

This study was approved by the Ethics Research Committee of the Institute of Health Sciences, Federal University of Bahia (Protocol No. 1.393.120) and by the Ethics Research Committee of the "Aristides Maltez" Hospital (Protocol No. 1.466.211).

\section{Results}

Table 1 shows socio-demographic data, in which predominance of males $(72.7 \%)$, single individuals $(50 \%)$, and low educational level $(88.1 \%)$ was observed. Minimum age was 20 years and maximum age was 94 years, with an average age of 57 years. Regarding the age group, threw was a predominance of patients aged 60-69 years (27.3\%). The patients' occupational profiles revealed that $38.3 \%$ were rural workers, the majority living in the state countryside (70.2\%). Regarding histopathological diagnosis, squamous cell carcinoma (89\%) predominated, followed by adenocarcinoma (5.8\%). The most frequent anatomical sites were tongue (26.6\%) and lip (13\%) (Table 1).

Table 1. Distribution of patients according to socio-demographic data, distribution of lesions according to histological type and location.

\begin{tabular}{|c|c|c|}
\hline Variables & $\mathbf{N}$ & $\%$ \\
\hline \multicolumn{3}{|l|}{ Sex } \\
\hline Female & 42 & 27.3 \\
\hline Male & 112 & 72.7 \\
\hline \multicolumn{3}{|l|}{ Age Group } \\
\hline 20-29 Years & 6 & 3.9 \\
\hline 30-39 Years & 10 & 6.5 \\
\hline 40-49 Years & 29 & 18.8 \\
\hline 50-59 Years & 39 & 25.3 \\
\hline 60-69 Years & 42 & 27.3 \\
\hline 70-79 Years & 20 & 13.0 \\
\hline 80-89 Years & 5 & 3.3 \\
\hline 90-99 Years & 3 & 1.9 \\
\hline
\end{tabular}




\begin{tabular}{|c|c|c|}
\hline \multicolumn{3}{|l|}{ Marital Status } \\
\hline Single & 77 & 50.0 \\
\hline Married & 53 & 34.4 \\
\hline Divorced & 3 & 2.0 \\
\hline Single & 13 & 8.4 \\
\hline No Information & 8 & 5.2 \\
\hline \multicolumn{3}{|l|}{ Place of Residence } \\
\hline Metropolitan Area of Salvador & 45 & 29.2 \\
\hline State Countryside & 109 & 70.8 \\
\hline \multicolumn{3}{|l|}{ Educational Level } \\
\hline Illiterate & 35 & 22.7 \\
\hline Complete / Incomplete Elementary School & 91 & 59.1 \\
\hline Complete / Incomplete High School & 25 & 16.2 \\
\hline Higher Education or Over & 3 & 1.9 \\
\hline \multicolumn{3}{|l|}{ Occupation } \\
\hline Farmer & 59 & 38.3 \\
\hline Housewife & 11 & 7.1 \\
\hline Driver & 7 & 4.6 \\
\hline Mason & 5 & 3.2 \\
\hline Mechanics & 5 & 3.2 \\
\hline Freelancer & 4 & 2.6 \\
\hline Teacher & 4 & 2.6 \\
\hline No Information & 7 & 4.6 \\
\hline Others & 52 & 33.8 \\
\hline \multicolumn{3}{|l|}{ Histopathological Diagnosis } \\
\hline Squamous Cell Carcinoma & 137 & 89.0 \\
\hline Adenocarcinoma & 9 & 5.8 \\
\hline Others ${ }^{1}$ & 5 & 3.2 \\
\hline Sarcoma & 3 & 2.0 \\
\hline \multicolumn{3}{|l|}{ Anatomical Sites } \\
\hline Others ${ }^{2}$ & 52 & 33.8 \\
\hline Tongue & 41 & 26.6 \\
\hline Lip & 20 & 13.0 \\
\hline Palate & 17 & 11.0 \\
\hline Mouth Floor & 10 & 6.5 \\
\hline Jugal Mucosa & 9 & 5.8 \\
\hline Gingival Border & 5 & 3.2 \\
\hline
\end{tabular}

Excessive tobacco $(65.6 \%)$ and / or alcohol (61\%) consumption was considered to be risk factors for HNC in this study (Table 2). Poor oral hygiene detected in $94 \%$ of patients was considered to be an important factor that enhances the deleterious action caused by tobacco and alcohol consumption. Records of the initial smoking age are relevant, which varied between 6 and more than 30 years in the evaluated sample. The initial smoking age is also noteworthy, between 6 and 10 years, referred by 13 patients (16.9\%), followed by the age between 11 and 19 years (38 patients / 49.3\%), indicating the beginning of smoking at early childhood and adolescence. It is also important to highlight the use of different forms of tobacco among participants, with emphasis on cigarettes $(40 \%)$, the most consumed variety, followed by straw and pipe cigarettes. Of the 94 patients who reported alcohol consumption, the age at which the habit started was between 9 and 34 years of age. Of these, $40.9 \%$ patients reported starting consuming alcohol at age between 9 and 19 years. 
Table 2. Distribution of patients according to tobacco and alcohol use.

\begin{tabular}{lcc}
\hline \multicolumn{1}{c}{ Variables } & $\mathbf{N}$ & $\mathbf{\%}$ \\
\hline Tobacco Use & & \\
No & 51 & 33.1 \\
Yes & 101 & 65.6 \\
No Information & 2 & 1.3 \\
Alcoholism & & \\
No & 60 & 39.0 \\
Yes & 94 & 61.0 \\
\hline
\end{tabular}

The present study also investigated the relationship between the use of alcoholic beverages and tumor size, presence of nodules and metastases related to the clinical staging of the lesion. As shown in Table 3, $82.9 \%$ of alcoholic patients had tumor with dimension classified as T4; in contrast, only $17.1 \%$ of those who did not use alcohol had tumors that received this classification. This difference between groups was statistically significant $(\mathrm{p}=0.030)$. Other associations were found between alcohol consumption and presence of nodules $(\mathrm{p}<0.01)$, with differences greater than $70 \%$ between greater consumption of this substance and presence of nodules $(p<0.00)$. However, the association with alcohol was less significant in terms of the occurrence of metastases due to the lower number of cases found in this condition $(6 / 75 \%)$.

Table 3. Association between alcohol use and tumor size, presence of tumor nodules and occurrence of metastases.

\begin{tabular}{lccccccc}
\hline TNM Classification & \multicolumn{2}{c}{ No } & \multicolumn{2}{c}{ Yes } & \multicolumn{2}{c}{ Total } & p-value \\
& $\mathrm{N}$ & $\%$ & $\mathrm{~N}$ & $\%$ & $\mathrm{~N}$ & $\%$ & \\
\hline Tumor Size & & & & & & & 0.030 \\
1 & 15 & 48.4 & 16 & 51.6 & 31 & 100.0 & \\
2 & 13 & 40.6 & 19 & 59.4 & 32 & 100.0 & \\
3 & 18 & 41.9 & 25 & 58.1 & 43 & 100.0 & \\
4 & 6 & 17.1 & 29 & 82.9 & 35 & 100.0 & \\
Nodules & & & & & & & 0.001 \\
0 & 51 & 47.2 & 57 & 52.8 & 108 & 100.0 & \\
1 & 1 & 5.6 & 17 & 94.4 & 18 & 100.0 & \\
2 & 1 & 16.7 & 5 & 83.3 & 6 & 100.0 & \\
3 & 2 & 25.0 & 6 & 75.0 & 8 & 100.0 & \\
Metastasis & & & & & & & 0.071 \\
$\quad$ No & 54 & 40.6 & 79 & 59.4 & 133 & 100.0 & \\
Yes & 2 & 25.0 & 6 & 75.0 & 8 & 100.0 & \\
\hline
\end{tabular}

The possibility of similar correlations between staging of lesions and tobacco consumption was also evaluated; however, results did not show statistical significance, as the relationship between tumor size and tobacco consumption $(\mathrm{p}=0.071)$, presence of nodules and tobacco consumption $(\mathrm{p}=0.216)$ and presence of metastasis and tobacco consumption $(\mathrm{p}=0.156)$.

Analyzing tobacco and alcohol consumption data of the investigated population in the period from 2008 to 2015 together, of which 74 patients (53.2\%) used both substances, the importance of this synergism was shown when its association with the classification of tumors by the TNM system was verified. Regarding tumor size, it was found that $19(45.2 \%)$ patients who consumed both substances had tumor classified as T3 and $26(74.3 \%)$ had tumor classified as $\mathrm{T} 4$, as shown in Table 4.

The synergism between alcohol and smoking also showed its significance in the presence of nodules, and it was observed that $75 \%$ of patients who consumed both substances were classified as N3 ( $\mathrm{p}=0.13)$. Data 
analysis also revealed the presence of metastases in patients who accumulated both habits, showing a percentage of $62.5 \%(\mathrm{p}=0.13)$ (Table 4$)$.

Table 4. Association between alcohol and tobacco consumption and tumor size, presence of nodules and presence of metastasis.

\begin{tabular}{|c|c|c|c|c|c|c|c|c|c|}
\hline \multirow{2}{*}{$\begin{array}{c}\text { TNM } \\
\text { Classification }\end{array}$} & \multicolumn{2}{|c|}{$\begin{array}{l}\text { No Alcohol and } \\
\text { Tobacco Use }\end{array}$} & \multicolumn{2}{|c|}{$\begin{array}{c}\text { Alcohol or } \\
\text { Tobacco Use }\end{array}$} & \multicolumn{2}{|c|}{$\begin{array}{l}\text { Alcohol and } \\
\text { Tobacco Use }\end{array}$} & \multicolumn{2}{|c|}{ Total } & \multirow[t]{2}{*}{ p-value } \\
\hline & $\mathrm{N}$ & $\%$ & $\mathrm{~N}$ & $\%$ & $\mathrm{~N}$ & $\%$ & $\mathrm{~N}$ & $\%$ & \\
\hline Tumor Size & & & & & & & & & 0.04 \\
\hline 1 & 10 & 33.3 & 6 & 20.0 & 14 & 46.7 & 30 & 100.0 & \\
\hline 2 & 10 & 31.3 & 7 & 21.9 & 15 & 46.9 & 32 & 100.0 & \\
\hline 3 & 10 & 23.8 & 13 & 31.0 & 19 & 45.2 & 42 & 100.0 & \\
\hline 4 & 2 & 8.6 & 6 & 17.1 & 26 & 74.3 & 35 & 100.0 & \\
\hline Nodules & & & & & & & & & 0.019 \\
\hline $\mathrm{O}$ & 32 & 30.19 & 27 & 25.47 & 47 & 44.3 & 106 & 100.0 & \\
\hline 1 & $\mathrm{O}$ & 0.0 & 5 & 27.78 & 13 & 72.2 & 18 & 100.0 & \\
\hline 2 & 1 & 16.67 & 1 & 16.67 & 4 & 66.7 & 6 & 100.0 & \\
\hline 3 & 1 & 12.50 & 1 & 12.50 & 6 & 75.0 & 8 & 100.0 & \\
\hline Metastasis & & & & & & & & & 0.091 \\
\hline No & 34 & 26.0 & 30 & 22.9 & 67 & 51.2 & 131 & 100.0 & \\
\hline Yes & $\mathrm{O}$ & 0 & 3 & 37.0 & 5 & 62.5 & 8 & 100.0 & \\
\hline
\end{tabular}

\section{Discussion}

Patients with HNC compose a typical and easily identifiable group, mostly men, with low purchasing power and low educational level, with difficulties in accessing health services, users of alcohol and / or tobacco or dependent on these substances [10]. These data corroborate those described in this study's sociodemographic profile, adding the age group of 60-69 years as the most prevalent.

The main predictors of the survival pattern for $\mathrm{HNC}$ in practically all sites are related to the age of diagnosis, diagnosis staging, smoking history and anatomical location [1]. Thus, in the present study, according to results obtained, it was observed that the most prevalent age for diagnosis of the disease was between 60 and 69 years, with preferably advanced diagnostic stages, smoking was present in $65 \%$ of the sample and the most frequent location was the tongue. Most patients who reported tobacco consumption reported doing it for a period between 11 to 19 years.

According to information recorded in literature, tobacco is the largest preventable cancer cause in the world, accounting for about 30\% of all cancer deaths in developing countries, including oropharyngeal and stomach cancer [2,13]. These risk factors are present in most studies that verify habits associated with the incidence of these neoplasms, as well as in the collection performed here, where $65.5 \%$ of participants were smokers and $61.0 \%$ were considered chronic alcoholics. Other researchers have managed to associate factors alcohol and tobacco with the development of malignancies [8]. However, they were unable to observe the correlation of other possible factors mentioned in the literature, such as viral infections, diet, and genetics, among others [8]. In the present study, these data were not collected and it was not intended to carry out this correlation.

It is estimated that there are more than one and a half billion smokers in the world today, and that number is expected to reach two billion by 2030, most of them concentrated in developing countries. The consumption of tobacco and its derivatives kills millions of individuals each year and, if the current trend continues, there will be 8 million deaths per year in 2030, $80 \%$ in low- and middle-income countries [2]. 
There is a wide variety of tobacco derivatives, used in different ways - smoked / inhaled (cigarette, pipe, cigar, bali or kretek cigarette or clove cigarette, straw cigarette, cigarillo, bidi, hookah); aspirated (snuff tobacco); chewed (roll tobacco, snuff); absorbed by the oral mucosa (snus) - all of which contain nicotine, cause addiction and dependence. The form of tobacco use is related to cancer type and location [13]. Among the risk factors for oral cancer are diabetes, shammah, a traditional tobacco cigarette used in the Arabian Peninsula, and betel, smoked in India and China [14]. In the present study, information on the type of tobacco consumed was observed, and the percentage of industrialized cigarette users is relevant, different from other regions in Brazil and in the world. However, it should be emphasized that all forms of tobacco, whether aspirated, chewed, smoked or inhaled, are absorbed by the oral mucosa, contain nicotine and cause addiction and dependence.

Cigarette contains 4,720 toxic substances, including carbon monoxide, ammonia, ketones, formaldehyde, acetaldehyde, acrolein, 65 of which are proven carcinogenic substances such as arsenic, nickel, benzopyrene, cadmium, lead, pesticide residues and radioactive substances, which makes cigarette a complete carcinogen, that is, cancer inducer and promoter [15].

Alcohol is known to be a risk factor related to oral cancer, in addition to others such as pharynx, esophagus, liver and breast cancer in women, but there are, to date, no records related to or determining the exact mechanism of its carcinogenic action. Evidence suggests that its effect is modulated by genetic polymorphisms that alter ethanol and folate metabolism and DNA repair [13]. Therefore, it is reasonable to conclude that alcohol alone cannot be associated with the initiating phase of oral carcinogenesis, but it is believed that it can promote it by enhancing the carcinogenic effects of tobacco [16]. Thus, alcohol is considered a cancer-promoting agent.

Different types and uses of tobacco and alcohol can characterize incidence and mortality from oral cancer in different regions of Brazil [6,7], highlighting that the Brazilian geographic regions, due to their cultural, demographic, socioeconomic heterogeneity (industrialization and urbanization degree, for example) and policies, have their populations submitted to different risk factors, the same occurring in relation to access to cancer diagnosis and treatment, quality of assistance, diagnostic capacity and quality of the information provided.

The findings related to tobacco consumption are surprising due to their significant value that can be attributed to some peculiarities. Of the 101 individuals $(65.6 \%)$ who reported having smoking habit, a large portion referred to the use of industrialized cigarettes, which production meets institutionalized regulations, with inspections and marketing authorization. This fact allows better control of chemical substances involved in the manufacture.

More and more tobacco has been recognized as a great carcinogenic agent, being extremely harmful to the health of users, and its harm effects have been admitted and extended to passive smokers, from which different ways of curbing its use have been created, particularly in public spaces.

However, in relation to alcohol, an attenuated situation is observed, and this habit is very widespread and accepted in social circles with extreme conformism. Considering individuals treated at HAM in the period from 2008 to 2015 , it is noteworthy that 94 individuals $(61 \%)$ reported the habit of consuming alcohol. The importance of analyzing these elements is related to the possible inexistence or weak surveillance regarding the manufacture and commercialization of distilled alcoholic beverages. It is known that, mainly in rural areas, many of these distillates are made in private stills and sold without any type of inspection, that is, various products whose potential for damaging health is unknown may be included in their composition. 
The study developed at the Brazilian Center for Information on Psychotropic Drugs (CEBRID) of the Federal University of São Paulo (UNIFESP), with support from the International Center for Alcohol Policies (ICAP) and countries like Russia, China, India, Mexico and Sri Lanka should be highlighted [17]. In relation to Brazil, this study analyzed samples of beverages such as cachaça, counterfeit whiskey and homemade liqueurs - clandestinely produced in seven municipalities in the states of São Paulo and Minas Gerais. The results pointed out the presence of toxic substances, such as copper - a metal that causes serious damage to the absorption of other minerals - and ethyl carbamate - a carcinogen agent - having also registered the presence of methanol, an extremely toxic type of alcohol, which ingestion can cause blindness and even death.

It is known that alcohol metabolism increases the production of free radicals and decreases antioxidant mechanisms, causing oxidative stress. Based on a significant literature review, it was emphasized that the genetic polymorphism of alcohol-degrading enzymes may be responsible for the difference in individual sensitivity and that certain isoforms of these enzymes allow the accumulation of toxic metabolites such as acetaldehyde, a substance that can cause damage to DNA or other cellular structures [18].

A relevant finding of this study is about the relationship between tobacco and alcohol consumption and the presence of metastases, which can certainly be confirmed by the increasing number of medical records that register the detection of oral and oropharyngeal cancer. The achievement of this goal can surely find reports of metastases and possible associations with the harmful habits discussed in the present study.

Results found in this study indicate that the association between "heavy" alcohol and tobacco consumption and tumor size is consistent. The interaction patterns between tobacco and alcohol have been varied, being represented by multiplicative or additive effects between both, with the presence of a multiplicative effect of risk when the association of both.

Several researchers have emphasized the importance of the simultaneous participation of tobacco and alcohol in the development of oral cancer, corroborating the percentages of $92.2 \%$ of smokers and $81.2 \%$ of alcoholics among individuals participating in the study [19]. The effect of the simultaneous use of alcohol and tobacco can increase the risk of developing oral cancer by up to 100 times [16]. Another study also emphasizes alcohol and tobacco consumption associated with the prognosis of oral cancer, emphasizing that the greater the consumption, the worse the disease conditions [12].

The relationship between smoking and oral squamous cell carcinoma is well established in literature. A similar study carried out in Bahia, Brazil, showed that smokers were four times more likely to develop oral cancer and that individuals who smoked more than 20 cigarettes daily were six times more likely to develop the same type of cancer [11]. Regarding the frequency of alcohol consumption, the authors showed that those who drank with high frequency had a high risk of developing oral cancer. In the present study, the relationship between the presence of the habit and development of oropharyngeal cancer was not established, but rather an assessment of how much the presence of the habit could interfere with the tumor's staging parameters. It was observed that both alcohol alone and the associated use of alcohol and tobacco interfered in the individuals' TNM classification. It was inferred that the presence and maintenance of this habit can lead to faster and more aggressive tumor lesions. Interestingly, the relationship between smoking habit and the degrees of clinical staging of the disease has not been established. This information can lead to the initial conclusion that smoking can be an excellent initiator, but would not be a potent disease promoter. However, the inclusion of a more significant $\mathrm{n}$ sample in an attempt to repeat correlation tests would be important in confirming this hypothesis.

Knowledge of the epidemiology and factors associated with this disease is the key to the planning of prevention programs that will favor the reduction of these harmful indicators [20,21]. The synergistic tobacco and alcohol consumption increases the risk of developing this neoplasm [9]. 
Similar to results observed in previous study [10], which showed that there was a predominance of patients with extensive tumors, with locoregional metastasis and at late diagnosis staging, in this study, this clinical characteristic was also observed, in particular, associated with the deleterious habits already mentioned. The results of this study corroborate those of aforementioned authors, who reported that these findings reflect the Brazilian reality, whose services specialized in head and neck tumors still receive patients with extensive injuries due to the lack of information on cancer prevention. These data are also confirmed by other authors [8], who reported that patients usually seek health services when the lesion is in an advanced stage, which makes treatment difficult, worsening the prognosis and reducing the survival rate.

This study is relevant for bringing data about the possible effect of alcohol, associated or not with smoking, as an important influence on the progression of head and neck cancer. It also characterizes and reinforces the profile of the affected patient and his / her harmful habits, in an attempt to warn professionals about the educational and preventive role of this population. It is important to emphasize the need for public authorities to assume their role of assistance at all levels of complexity, establishing quality public policies for health promotion and cancer treatment.

\section{Conclusion}

The sample of this study was predominantly composed of men with low educational level aged over 60 years, living in the state countryside and rural workers. Individuals with head and neck cancer were exposed to tobacco and alcohol, known risk factors for neoplasms in this region. There was a strong association between use of alcohol and tumors with T3 / T4 staging, as well as the presence of nodules. This finding, aggravated by the use of alcohol associated with tobacco, leads to the possibility of an inducing carcinogenic action. It was observed that the cumulative use of alcohol and tobacco demonstrated strong association and possible carcinogenic action. However, it was not possible to correlate this possibility of action with the use of tobacco.

\section{Authors' Contributions}

\begin{tabular}{|c|c|c|}
\hline CMGS & (iD) $0000-0002-1285-5458$ & $\begin{array}{l}\text { Conceptualization, Methodology, Investigation and Writing - Original Draft } \\
\text { Preparation. }\end{array}$ \\
\hline DBA & (iD) $0000-0002-4822-0390$ & Formal Analysis, Data Curation and Writing - Review and Editing. \\
\hline GBM & (iD) $0000-0002-0917-4598$ & Formal Analysis, Data Curation and Writing - Review and Editing. \\
\hline EJC & (iD) $0000-0002-7751-0493$ & Formal Analysis, Data Curation and Writing - Review and Editing. \\
\hline $\mathrm{RPCA}$ & (iD) $0000-0001-7648-728 \mathrm{X}$ & $\begin{array}{l}\text { Conceptualization, Methodology, Supervision, Writing }- \text { Original Draft } \\
\text { Preparation and Writing - Review and Editing. }\end{array}$ \\
\hline
\end{tabular}

\section{Financial Support}

None.

\section{Conflict of Interest}

The authors declare no conflicts of interest.

\section{References}

[1] Abrahão R, Anantharaman D, Gaborieau V, Abedi-Ardekani B, Lagiou P, Lagiou A, et al. The influence of smoking, age and stage at diagnosis on the survival after larynx, hypopharynx and oral cavity cancers in Europe: The ARCAGE study. Int J Cancer 2018; 143(1):32-44. https://doi.org/10.1002/ijc.31294 
[2] Instituto Nacional do Câncer (INCA). Estimativa 2008. Incidência de Câncer no Brasil. Available from: http://bvsms.saude.gov.br/bvs/publicacoes/estimativa_incidencia_cancer_2008.pdf. [Accessed on December 14, 2018]. [In Portuguese].

[3] Kadashetti V, Shivakumar KM, Chaudhary M, Patil S, Gawande M, Hande A. Influence of risk factors on patients suffering from potentially malignant disorders and oral cancer: a case-control study. J Oral Maxillofac Pathol 2017; 21(3):455-6. https://doi.org/10.4103/jomfp.JOMFP_236_14

[4] Favero E, Bittencourt M, Andrade Júnior A, Cyrillo CG, Ferraz LGC, Franzi SA. Epidemiological profile of Grande São Paulo patients with oral and oropharyngeal advanced squamous cell carcinoma. Rev Bras Cir Cabeça Pescoço 2007; 36(3):155-8.

[5] Leite ICG, Koifman S. A review of risk factors for oral and pharyngeal cancer. Rev Bras Cancerol 1988; 44(4):317-25.

[6] Amorim Filho FS, Andrade Sobrinho J, Rapoport A, Carvalho MB, Novo NF, Juliano Y. Study of demographic, ocupacional and co-carcinogenetics factors in squamous cell carcinoma of base of the tongue in women. Rev Bras Otorrinolaringol 2003; 69(4):472-8. https://doi.org/10.1590/So034-72992003000400006

[7] Wunsch-Filho V. The epidemiology of bucal and pharynx cancer in Brazil. Oral Oncol 2002; 38(8):737-46. https://doi.org 10.1016/s1368-8375(02)00066-0

[8] Cedraz JSB, Nascimento FM, Menezes FS, Takeshita WM, Santos NCN, Trento CL, et al. Clinical and epidemiological study in patients with oral cancer in a period of thirteen years. Rev Cuba Estomatol 2016; 53(3):8696.

[9] Andrade JOM, Santos CADT, Oliveira MC. Associated factors with oral cancer: a study of case control in a population of the Brazil's Northeast. Rev Bras Epidemiol 2015; 18(4):894-905.

https://doi.org/10.1590/1980-5497201500040017

[10] Santos RA, Portugal FB, Felix JD, Santos PMO, Siqueira MM. Epidemiological evaluation of patients with cancer in the upper aerodigestive tract: relevance of alcohol and tobacco risk factors. Rev Bras Cancerol 2012; 58(1):21-9.

[11] Antunes RCP, Perdicaris AAM, Gomes R. Prevenção do Câncer. 2nd. ed. São Paulo: Manole; 2015. 640p. [In Portuguese].

[12] Santos LPS, Carvalho FS, Carvalho CAP, Santana DA. Characteristics of cases of oral cancer in the state of Bahia, 1999-2012: a hospital-based study. Rev Bras Cancerol 2015; 61(1):7-14.

[13] Torres-Pereira CC, Angelim-Dias A, Melo NS, Lemos Jr. CA, Oliveira EMF. Strategies for management of oral cancer in primary and secondary healthcare services Cad Saúde Pública 2012; 28(Supl.):S30-S39. https://doi.org/10.1590/So102-311X2012001300005

[14] Bagan JV, Scully C. Recent advances in oral oncology 2007: epidemiology, aetiopathogenesis, diagnosis and prognostication. Oral Oncol 2008; 44(2):103-8. https://doi.org/10.1016/j.oraloncology.2008.01.008

[15] Rosemberg J, Rosemberg AMA, Moraes MA. Nicotina: Droga Universal. São Paulo: SESC/CVE; 2004. 178p. [In Portuguese].

[16] Bonfante GMS, Machado CJ, Souza PEA, Andrade EIG, Acurcio FA, Cherchiglia ML. Specific 5-year oral cancer survival and associated factors in cancer outpatients in the Brazilian Unified National Health System. Cad Saúde Pública 2014; 30(5):983-97. https://doi.org/10.1590/0102-311X00182712

[17] Cruz F. Bebidas alcoólicas clandestinas podem conter substâncias tóxicas, aponta estudo da Unifesp. Available from: $<$ http://memoria.ebc.com.br/agenciabrasil/noticia/2012-10-30/bebidas-alcoolicas-clandestinas-podem-contersubstancias-toxicas-aponta-estudo-da-unifesp >. [Accessed on November 17, 2016]. [In Portuguese]

[18] Carrard VC, Pires AS, Paiva RL, Chaves ACM, Sant'Ana Filho M. Alcohol and oral cancer: comments on related mechanisms. Rev Bras Cancerol 2008; 54(1):49-56.

[19] Miller CS, Henry RG, Rayens MK. Disparities in risk of and survival from oropharyngeal squamous cell carcinoma. Oral Surg Oral Med Oral Pathol Oral Radiol Endod 2003; 95(5):570-5. https://doi.org/10.1067/moe.2003.108

[20] Santos GBG, Wanderley AEC, Menezes PL, Santos VCB, Barbosa KGN, Ferreira SMS. Smoking-alcohol-sex exposure and knowledge about oral and oropharyngeal cancer among Brazilian adolescents: an exploratoryobservational approach. Pesqui Bras Odontopediatria Clín Integr 2020; $20: e 5298$. https://doi.org/10.1590/pboci.2020.084

[21] Wimardhani YS, Soegyanto AI, Pratiwi AR. Oral cancer knowledge among a sample of elderly people in Depok City, West Java, Indonesia. Pesqui Bras Odontopediatria Clín Integr 2018; 18(1):e4092. https://doi.org/10.4034/PBOCI.2018.181.76 